Review

\title{
Association between Oral Frailty and Geriatric Conditions
}

\author{
Koji Naruishi ${ }^{*}$
}

Department of Periodontology and Endodontology, Tokushima University Graduate School of Biomedical Sciences, Tokushima 770-8504, Japan; E-Mail: naruishi@tokushima-u.ac.jp

* Correspondence: Koji Naruishi; E-Mail: naruishi@tokushima-u.ac.jp

Academic Editor: Lisa Hollis-Sawyer

Special Issue: Got Aging? Examining Later-life Development from a Positive Aging Perspective

\section{OBM Geriatrics}

2018, volume 2 , issue 4

doi:10.21926/obm.geriatr.1804016
Received: September 06, 2018

Accepted: October 16, 2018

Published: October 26, 2018

\begin{abstract}
In Japan, the amount of aged hospitalized patients has been steadily increasing. Elderly people are susceptible to poor health, and the rise of elderly patients increases medical care expenses, which can cause economic strain. Therefore, it is clinically and socially important to reduce the occurrence of geriatric diseases, such as aspiration pneumonia and cognitive impairment. The daily care by family members is considered to be effective for the prevention of geriatric diseases, however, early detection of the disease risk should receive more clinical significance. If risk factors are detected early by the caregivers or their family members, relevant preventive daily care may be provided in their home before the occurrence of geriatric disease. This review article focused on oral conditions of hospitalized aged patients and examined the effects of co-existing risk factors, such as oral frailty, on geriatric conditions.
\end{abstract}

\section{Keywords}

Oral frailty; geriatric conditions; elderly patients

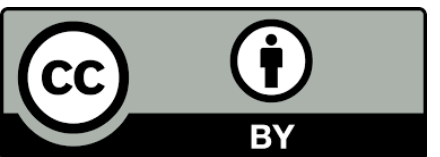

(C) 2018 by the author. This is an open access article distributed under the conditions of the Creative Commons by Attribution License, which permits unrestricted use, distribution, and reproduction in any medium or format, provided the original work is correctly cited. 


\section{Introduction}

Elderly people are susceptible to poor health, and the hospitalization of the elderly has been steadily increasing worldwide [1]. It is well known that the incidence of various geriatric diseases increases dramatically during old age. It is important to reduce the occurrence of geriatric diseases, such as aspiration pneumonia and cognitive impairment, both clinically and socially in order to prevent excessive rises in medical expenses. Previously, Baik et al. reported that both smoking and excessive weight loss are risk factors for community-acquired pneumonia [2]. Additionally, aspiration of oral pathogens is considered to be a major cause of nursing home-acquired pneumonia in aged people. Importantly, it has been reported that there is a statistical relationship between pneumonia and cognitive impairment in elderly patients [3]. Moreover, malnutrition is correlated with several parameters of poor oral health such as poor hygiene, swallowing disorders, and impaired movements of the tongue $[4,5]$. Although the strict mechanisms of malnutritionmediated aspiration pneumonia are still unclear, poor oral health is likely an important direct or indirect inducer of the disease since frequent silent aspiration is associated with disease activity in elderly patients [6]. These findings indicate that there are many risk factors involved in the occurrence of aspiration pneumonia.

Aspiration pneumonia is a fatal disease and definitively diagnosed by medical doctors. Biomarkers may be useful for the accurate diagnosis of diseases in elderly patients, especially during the acute phase [7]. However, in a clinical setting of geriatric nursing care, using simple methods for risk evaluation of geriatric diseases in elderly patients may be useful. Since the daily care by their family is also considered to be effective for the prevention of geriatric diseases, early detection of disease risk would be more clinically useful. Relevant preventive daily care may be provided in their home before the occurrence of disease if several risk factors are detected early by the caregivers, including their family members.

Our study demonstrated the clinical significance of oral condition to the development of geriatric diseases. The present review article focused on oral conditions of hospitalized elderly patients and described the effects of co-existing risk factors, such as oral frailty, on the geriatric condition.

\section{Relationship of Oral Frailty to the Occurrence of Aspiration Pneumonia}

To predict the occurrence of aspiration pneumonia effectively, establishment of simple examination systems should be considered in the geriatric field. A cross-sectional study showed that an unclosed mouth and impaired movements of the tongue, which are related to the strength of the oral muscle, were associated with the development of aspiration pneumonia [8]. Furthermore, significant association was also found between loss of posterior occlusion and occurrence of the disease [8]. Recently, "oral frailty" was defined as poor oral conditions, such as unclosed mouth, impaired movements of the tongue, and loss of posterior occlusion. Additionally, periodontitis is an infectious disease that may result in loss of teeth by inflammation-induced alveolar bone resorption [9]. Loss of posterior occlusion is an unwanted consequence of severe periodontitis, resulting in impaired activity of the masticatory muscle. Consequently, oral pathogens are easily aspirated into the bronchial tubes, resulting in the occurrence of aspiration pneumonia through oral frailty in elderly patients with periodontitis. 


\section{Relationship of Low BMI to the Occurrence of Aspiration Pneumonia}

Biomarkers, such as serum albumin levels, may be used frequently for the evaluation of nutritional conditions in elderly patients. Malnutrition is a significant risk factor for the progression of geriatric diseases, such as aspiration pneumonia. However, biomarkers may not be always available, because blood tests are often difficult and limited by the patient's refusal and costs [10]. On the other hand, body mass index (BMI) is a useful clinical indicator of nutritional conditions, which is defined by a person's weight and their height [11]. It has been generally accepted that both low and high BMIs are associated with the progression of several diseases. In particular, a high BMI is associated with an increased risk of hypertension, hyperlipidemia, and diabetes in middle-aged people [12], whereas a low BMI is associated with cognitive impairment in old-aged people [10]. In addition, close relationships were observed between low BMIs and the occurrence of aspiration pneumonia [13]. For the clinical use of BMI values in the geriatric field, ROC analyses were performed to determine the cut-off value of $\mathrm{BMI} ; 19.0 \mathrm{~kg} / \mathrm{m}^{2}$ was determined to distinguish the occurrence of geriatric diseases such as aspiration pneumonia, cerebrovascular disease, and cognitive impairment. According to the WHO [15], underweight is defined as a $\mathrm{BMI}<18.5 \mathrm{~kg} / \mathrm{m}^{2}$, overweight as a BMI between $25.0-29.9 \mathrm{~kg} / \mathrm{m}^{2}$, and obese as a $\mathrm{BMI} \geq 30.0 \mathrm{~kg} / \mathrm{m}^{2}$. Therefore, $19.0 \mathrm{~kg} / \mathrm{m}^{2}$ as a cut-off value of BMl seems accurate. A cross-sectional study showed that statistical relationships exist between low BMI and unclosed lips or impaired tongue movements [14]. Although the causal relationship between low BMI and occurrence of aspiration pneumonia is still unclear, it is possible to suggest that eating disorders in the elderly lead to malnutrition, and malnutrition-induced low BMI may lead to disordered swallowing function due to impaired oral muscles, resulting in the occurrence of aspiration pneumonia [16]. Since swallowing disorders lead to dehydration, malnutrition, and airway obstruction [17], close relationships between low BMI and occurrence of aspiration pneumonia are likely to be found in frail, elderly patients. Taken together, BMI is easy to evaluate, even for a non-medical person, and may be a useful tool to predict the risk of geriatric diseases before they begin, enabling preventative measures to be taken prior to onset.

\section{Effects of Oral Function on the Improvement of Functional Capacity after Rehabilitation in Hospitalized Elderly Patients}

In general, hospitalized elderly patients are rehabilitated by physiatrists, and their functional capacities are improved during the hospital stay. Through effective rehabilitation, almost all elderly patients are able to fully recover activities of daily living (ADL), and are then discharged back to their homes. A cross-sectional study showed that there is a significant relationship between improvement of swallowing function and recovery of ADL in stroke patients [18]. On the other hand, sometimes elderly patients cannot fully improve functional performance even after receiving the same rehabilitation, although the exact reason is still not elucidated. Recently, the Functional Independence Measure (FIM) score has been used as a relevant tool to evaluate the patient's physical function and assess rehabilitation outcomes in the geriatric field [13]. A retrospective study showed that closed lips and functional movements of the tongue were important parameters that contributed to the increase of FIM scores [13]. In addition, the stability of the posterior occlusion was also statistically associated with the increase. Therefore, oral 
function may be an important factor that may predict the improvement of ADL performances after rehabilitation in hospitalized elderly patients. A comprehensive evaluation of the factors involved in oral function may be useful to predict the success of rehabilitation effects in elderly patients.

\section{Evaluation for Discharge Destination in Elderly Inpatients}

Functional capacity in elderly patients after rehabilitation should be a significant factor in the decision of discharge destination. Since FIM scores reflect the performance of ADL in elderly patients, the FIM score may be a useful parameter to determine the discharge destination of elderly inpatients. In general, elderly patients with a low FIM may be discharged to a care facility, and those with a high FIM may be able to return to their home. ROC analyses determined the cutoff values of FIM scores suggested to their home (54 for men and 51 for women upon admission, and 76 for men and 85 for women at discharge) [19]. Interestingly, higher FIM scores may be required in female patients to return home after discharge in Japan. To clarify the differences between male and female FIM scores for the discharge destination decision, further clinical study is needed.

Furthermore, a cross-sectional study showed that tongue movement disorders and edentulism, which relates to oral muscle strength, are significant parameters for the discharge destination decision [20]. Interestingly, a number of elderly patients with tongue movement disorders and edentulism could not return to their home after discharge [20]. Clinically, edentulism may be a useful parameter to predict destination after discharge, since it is relatively easy to examine whether the patients are edentulous or not. These findings propose that collaboration with dentists may be useful in order to predict the destination after discharge in elderly inpatients.

\section{Effects of Swallowing Disorders on Life Prognosis of Elderly Patients}

Causes of death in old age are various, such as heart failure, vascular diseases, cancer, pneumonia, and senility [21]. Life prognosis may be often clinically indistinct, especially in elderly patients. Although people want to provide the best medical treatment for their loved ones at their end of life, the decision might often be difficult because they do not have sufficient knowledge about the prognosis [22]. Sometimes, fallacious judgment by families may result in unwanted pain to the elderly or excessive medical expenses to the families. Therefore, it is important for the families to predict the life prognosis of the elderly based on clinical and research evidence. Specifically, impaired physical function just before death may be useful to predict life prognosis [23]. Although impaired function may depend on organ failure and frailty, advanced judgement of life prognosis based on the objective evidence is required. A Kaplan-Meier analysis showed that the survival rate in elderly patients with impaired swallowing function was significantly lower than in patients with normal swallowing function [24]. Although the time of death of frail, elderly patients may be unclear, an examination of swallowing function, such as videoendoscopy, might be useful to evaluate the life prognosis of elderly patients.

\section{Conclusions}

A series of geriatric studies have shown the clinical effects of poor oral conditions on geriatric status (Table 1). In the geriatric field, a multidisciplinary clinical team, including the patient's family, 
is essential to the systemic stability of elderly patients. Since oral frailty and low BMI are significant risk factors for the occurrence of geriatric diseases such as aspiration pneumonia, collaboration with dentists may be useful to prevent the occurrence of unwanted diseases.

Table 1 Clinical effects of poor oral conditions to the geriatric status

\begin{tabular}{ccllc}
\hline Study style & Sample size & \multicolumn{1}{c}{ Oral conditions } & \multicolumn{1}{c}{ Geriatric status } & Ref No. \\
\hline Cross-sectional & 1,174 & $\begin{array}{l}\text { Loss of posterior } \\
\text { occlusion, Impaired } \\
\text { tongue movements }\end{array}$ & $\begin{array}{l}\text { Higher incidence of } \\
\text { aspiration } \\
\text { pneumonia }\end{array}$ & 8 \\
Retrospective & 262 & $\begin{array}{l}\text { Stable posterior } \\
\text { occlusion, Closed } \\
\text { lips, Functional } \\
\text { tongue movement }\end{array}$ & $\begin{array}{l}\text { Improvement of } \\
\text { FIM scores during } \\
\text { hospitalization }\end{array}$ & 13 \\
\hline Cross-sectional & 1,223 & $\begin{array}{l}\text { Loss of posterior } \\
\text { occlusion }\end{array}$ & Low BMI & 14 \\
\hline Cross-sectional & 257 & $\begin{array}{l}\text { Impaired tongue } \\
\text { movement, } \\
\text { Edentulous }\end{array}$ & $\begin{array}{l}\text { Elderly inpatients } \\
\text { cannot return } \\
\text { home after } \\
\text { discharge }\end{array}$ & 20 \\
\hline Retrospective & 320 & $\begin{array}{l}\text { Impaired swallowing } \\
\text { function }\end{array}$ & $\begin{array}{l}\text { Low survival } \\
\text { probability }\end{array}$ & 24 \\
\hline
\end{tabular}

\section{Acknowledgments}

I thank the medical staff of Naruto Seagull Hospital and Tottori Municipal Hospital for the clinical support.

\section{Author Contributions}

The author wrote and revised the manuscript.

\section{Funding}

This study was supported by a Grant-in-Aid for Scientific Research (C) (No. 16K11832) from the Japan Society for the Promotion of Science.

\section{Competing Interests}

The author has declared that no competing interests exist.

\section{References}

1. Arai $\mathrm{H}$, Ouchi $\mathrm{Y}$, Yokode $\mathrm{M}$, et al. Toward the realization of a better aged society: messages from gerontology and geriatrics. Geriatr Gerontol Int. 2012; 12: 16-22. 
2. Baik I, Curhan GC, Rimm EB, Bendich A, Willett WC, Fawzi WW. A prospective study of age and lifestyle factors in relation to community-acquired pneumonia in US men and women. Arch Intern Med. 2000; 160: 3082-3088.

3. Foley NC, Affoo RH, Martin RE. A systematic review and meta-analysis examining pneumoniaassociated mortality in dementia. Dement Geriatr Cogn Dis. 2015; 39: 52-67.

4. Cintra MT, de Rezende NA, de Moraes EN, Cunha LC, da Gama Torres HO. A comparison of survival, pneumonia, and hospitalization in patients with advanced dementia and dysphagia receiving either oral or enteral nutrition. J Nutr Health Aging. 2014; 18: 894-899.

5. van der Maarel-Wierink CD, Vanobbergen JN, Bronkhorst EM, Schols JM, de Baat C. Risk factors for aspiration pneumonia in frail older people: a systematic literature review. J Am Med Dir Assoc. 2011; 12: 344-354.

6. Momosaki R, Yasunaga H, Matsui H, Horiguchi H, Fushimi K, Abo M. Predictive factors for oral intake after aspiration pneumonia in older adults. Geriatr Gerontol Int. 2016; 16: 556-560.

7. Camina Martín MA, de Mateo Silleras B, Redondo del Río MP. Body composition analysis in older adults with dementia. Anthropometry and bioelectrical impedance analysis: a critical review. Eur J Clin Nutr. 2014; 68: 1228-1233.

8. Naruishi K, Nishikawa Y, Kido JI, Fukunaga A, Nagata T. Relationship of aspiration pneumonia to cognitive impairment and oral condition: a cross-sectional study. Clin Oral Investig. 2018; 22: $2575-2580$.

9. Armitage GC. Clinical evaluation of periodontal diseases. Periodontology. 2000 1995; 7: 39-53.

10. Mathys J, Gholamrezaee M, Henry H, von Gunten A, Popp J. Decreasing body mass index is associated with cerebrospinal fluid markers of Alzheimer's pathology in $\mathrm{MCl}$ and mild dementia. Exp Gerontol. 2017; 100: 45-53.

11. García-Ptacek $S$, Faxén-Irving G, Cermáková $P$, Eriksdotter $M$, Religa D. Body mass index in dementia. Eur J Clin Nutr. 2014; 68: 1204-1209.

12. Singh S, Dhingra S, Ramdath DD, Vasdev S, Gill V, Singal PK. Risk factors preceding type 2 diabetes and cardiomyopathy. J Cardiovasc Transl Res. 2010; 3: 580-596.

13. Naruishi K, Kunita A, Kubo K, Nagata T, Takashiba S, Adachi S. Predictors of improved functional outcome in elderly inpatients after rehabilitation: A retrospective study. Clin Interv Aging. 2014; 9: 2133-2141.

14. Naruishi K, Yumoto H, Kido Jl. Clinical effects of low body mass index on geriatric status in elderly patients. Exp Gerontol. 2018; 110: 86-91.

15. World Health Organization. Obesity: preventing and managing the global epidemic. Report of a WHO consultation. 2000; 894: 1-253.

16. Teramoto $\mathrm{S}$, Yoshida K, Hizawa N. Update on the pathogenesis and management of pneumonia in the elderly-roles of aspiration pneumonia. Respir Investig. 2015; 53: 178-184.

17. Fávaro-Moreira NC, Krausch-Hofmann S, Matthys C, Vereecken C, Vanhauwaert E, Declercq A, et al. Risk Factors for Malnutrition in Older Adults: A Systematic Review of the Literature Based on Longitudinal Data. Adv Nutr. 2016; 7: 507-522.

18. Nakayama $E$, Tohara $H$, Hino $T$, Sato $M$, Hiraba $H$, Abe $K$, et al. The effects of ADL on recovery of swallowing function in stroke patients after acute phase. J Oral Rehabil. 2014; 41: 904-911.

19. Naruishi K, Kunita A, Nagata T, Takashiba S, Adachi S. Cut-off values of Functional Independence Measure scores for discharge destination. Geriatr Gerontol Int. 2015; 15: 670671. 
20. Naruishi K. Association between Oral Conditions and Returning Home after Discharge in Elderly Patients. Geriatrics. 2017; 2: 28, doi:10.3390/geriatrics2030028

21. Hayashi $T$, Nomura $H$, Ina $K$, , Kato $T$, Hirose $T$, Nonogaki Z, et al. Place of death for the elderly in need of end-of-life home care: a study in Japan. Arch Gerontol Geriatr. 2011; 53: 242-244.

22. Jaul E, Zabari Y, Brodsky J. Spiritual background and its association with the medical decision of, DNR at terminal life stages. Arch Gerontol Geriatr. 2014; 58: 25-29.

23. Lunney JR, Lynn J, Foley DJ, Lipson S, Guralnik JM. Patterns of functional decline at the end of life. JAMA. 2003; 289: 2387-2392.

24. Naruishi K, Nishikawa Y. Swallowing impairment is a significant factor for predicting life prognosis of elderly at the end of life. Aging Clin Exp Res. 2018; 30: 77-80.

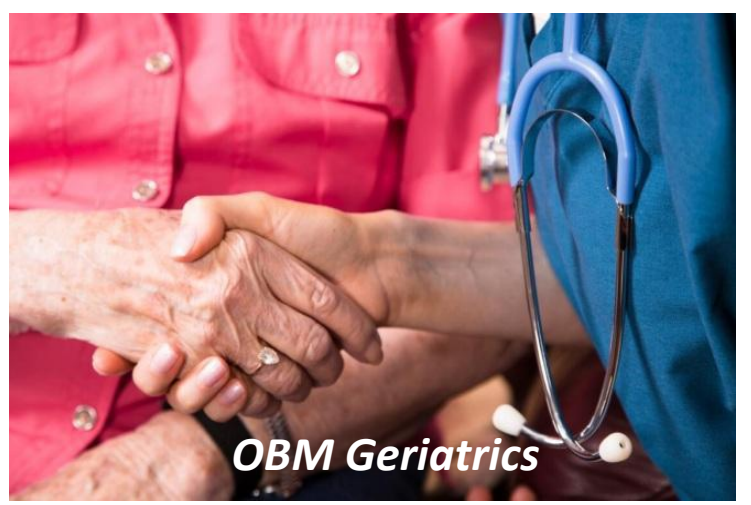

Enjoy OBM Geriatrics by:

1. Submitting a manuscript

2. Joining in volunteer reviewer bank

3. Joining Editorial Board

4. Guest editing a special issue

For more details, please visit: http://www.lidsen.com/journals/geriatrics 